\title{
CSE Program at ETH Zurich: Are We Doing the Right Thing?
}

\author{
Rolf Jeltsch \\ Seminar for Applied Mathematics \\ ETH Zurich \\ CH-8092 Zurich \\ jeltsch@math.ethz.ch \\ Kaspar Nipp \\ Seminar for Applied Mathematics \\ ETH Zurich \\ CH-8092 Zurich \\ nipp@math.ethz.ch
}

\section{Introduction}

Computational techniques, next to theory and experiments, have become a major and widespread tool to solve large problems in Science and Engineering. Especially in places where large computer power was available, such as in North America, Japan and Europe, the need was recognized to start to educate persons in the new discipline Computational Science and Engineering (CSE). A first survey of the state of affairs in this new subject is given in the report 'Graduate Education in Computational Science and Engineering' of the SIAM working Group [3].

At the Swiss Federal Institute of Technology (ETH) in Zurich, W. Gander (Institute for Scientific Computing, Computer Science), M. Gutknecht (Swiss Center for Scientific Computing until 1998, since 1999 Seminar for Applied Mathematics, Mathematics) together with R. Jeltsch (Seminar for Applied Mathematics, Mathematics) started the discussion of implementing CSE education at ETH in 1995. The first discussion was to find ways to add a CSE direction in each engineering and each science curriculum. This turned out not to be practical at that time, due mostly to the regulations amongst the curricula differing a lot. For example, this would have meant that one would have to teach several courses in Numerical Analysis with a different number of teaching hours per week, each for a very small number of students. Moreover, in the diploma degree received by a student, CSE would then only have been mentioned as a minor, if at all. The Executive Committee of ETH Zurich strengthened the group at the end of 1995 by making it a formal committee and adding two more members, W. van Gunsteren (Computational Chemistry, Chemistry) and K. Nipp (Seminar for Applied Mathematics, Mathematics).

In this article we describe the program developed by this committee. It leads to a Diploma (M.S.). The first students started in October 1997. Since then 
the curriculum has undergone minor modifications and we present here the one which will be in effect for students starting this year in fall.

The key elements of this curriculum are as follows. The overall study time to reach the Diploma in CSE should not be longer than the other curricula leading to a diploma at ETH, i.e., 4.5 years (9 Semesters). The curriculum should build upon other classical studies in engineering and sciences. A student would first study two years in one of these subjects before changing to the CSE curriculum which then would last only for 2.5 years ( 5 semesters). Depending on the knowledge a student has when entering the program, a certain number of supplementary courses have to be taken in order to bring all students to an approximately equivalent level of education.

In the present curriculum in CSE at ETH 'computational' is understood as mainly numerical computing, rather than logical computing or data bases. Hence a large portion of the curriculum is concerned with differential equations, ordinary and partial, optimization in all variations. In a sense we consider CSE a new expression superseding 'scientific computing' by being more applied. See for a comment on this in the interview of B. Engquist by O. Nevanlinna, [2].

In Section 2 we describe the curriculum in detail while in Section 3 we briefly mention the organizational structure. In Section 4 the experiences from the past are described and future development is touched upon. We finish with some conclusions in the last section.

\section{Curriculum at ETH}

\subsection{Design principles}

\section{a) Aim of curriculum}

When designing a new curriculum one should think of what a student should know, which abilities she or he should have acquired, when finishing successfully the program. Since ETH had no previous program in CSE we had the luxury to create the curriculum we felt would be best.

The major objectives and design principles are:

- The emphasis is on Science and Engineering and not just computing for the sake of computing, i.e., we want that the student knows what she or he is computing.

- Computing has to be an essential tool in any field taught.

- A student should make an in depth study in at least one or maybe two fields.

- A student should obtain a broad view and should have knowledge of many applications.

- A student should acquire the ability to work in a team. 
- A student should have the ability to work together with people from different backgrounds (e.g., he or she must be able to talk to the scientists and or engineers who know the application area and he or she must be able to talk to mathematicians and computer scientists because one can not expect of the person educated in CSE to know that much mathematics and computer science that he or she can solve all problems by himself or herself).

- A student should have the ability to enter quickly in an ongoing research project of a team, make his contribution and transmit it successfully to the team.

- A student should acquire communication abilities.

- The overall study time should not be longer as with other students at ETH, i.e., 4 years and an additional 4 months for the diploma thesis.

\section{b) ETH boundary conditions}

Some of the boundary conditions at ETH are time dependent, i.e., as time goes on they might change and then the CSE program will have to change too. Here are some of the conditions and their effect on the curriculum.

- Curricula at ETH in Zurich draw first semester students mostly from the German and Italian speaking part of Switzerland. The number of students therefore for a curriculum in CSE starting in the first semester is small and hence not very cost effective. Due to this, it was decided to start the curriculum only after two years of basic studies in an appropriate science or engineering curriculum. This has the additional side effect that the students come from different fields and learn on a daily basis do communicate with persons from other fields.

- Since we did not expect many students and ETH had already many courses which could be modified, such that these became excellent for our CSE curriculum, we wanted to use as many as possible existing courses. It is clear that as ETH acquires more lecturers in CSE and more departments add scientists who use computation as a major tool, the number of courses taught for the CSE students alone would increase. This has already happened. In the first year, only three courses were taught due to the CSE curriculum. In the next academic year this number will at least be doubled.

\subsection{Curriculum}

\section{a) Overview}

The above mentioned design principles have lead to the following curriculum which should be covered in four semesters. The hours mentioned in the second column are the number of hours per week in a semester added up over the four semesters. For example, the total of 83 hours means that each semester a student has approximately 21 hours of courses per week. 


\section{Overview of the Curriculum}

\begin{tabular}{lcl} 
& $\begin{array}{c}\text { Hours of work } \\
\text { per week } \\
\text { per semester }\end{array}$ & short description \\
\hline Core Courses & 37 & $\begin{array}{l}\text { methodology in mathematics, } \\
\text { computer science, } \\
\text { important application areas, } \\
\text { case studies }\end{array}$ \\
\hline Field of Specialization & 10 & $\begin{array}{l}\text { work in one computational } \\
\text { application area, } \\
\text { specialization }\end{array}$ \\
\hline Elective Courses & 12 & $\begin{array}{l}\text { must be CSE related } \\
\text { Two Term Papers }\end{array}$ \\
\hline 12 & $\begin{array}{l}\text { application oriented, } \\
\text { work in a team, } \\
\text { computational, at least } \\
\text { 180 hours of work }\end{array}$ \\
\hline Supplementary Courses & 12 & $\begin{array}{l}\text { to complete foundations } \\
\text { for CSE education }\end{array}$ \\
\hline
\end{tabular}

Total

83

In addition to this every student at ETH must acquire 8 credits from the department of Humanities, Social and Political Sciences during the four years of studies. The duration of the diploma thesis is four months and it is usually done after the four semesters of study.

\section{b) Core Courses}

The nine core courses consist of eight courses covering numerics of differential equations, parallel computing, optimization techniques, computational statistics, methods of computer-oriented quantum mechanics and statistical mechanics, software engineering, visualization and the so called 'case studies'. In these first eight core courses, a student learns CSE related methodologies which enables her or him to use these as problem solving tools. Clearly these eight courses are mandatory and they are offered each year. The course 'case studies' is offered each semester and it is mandatory for a student to participate. The case studies have two functions. Lecturers from ETH and specialists from outside institutions, from industry or academia, demonstrate in two lectures, each 45 minutes, one area of application from their own fields of work, from the modelling to the solution of the problem with the help of the computer. A list of topics treated in 
the winter semester 2001/2002 is added below. From this list one sees that students have to do presentations to improve their communication abilities. There are two types of student presentations. Each semester, every student has to give a ten minute presentation of a short scientific article. He or she can choose an article from literature after consultation with the course leader or can choose from a set of predetermined articles. Each presentation is followed by a question and answer session and a discussion of the communication skills. The second type of student presentation is the oral communication of the result of a term paper. The presentation lasts usually 20 - 30 minutes.

In the case studies, the student gets a broad overview and learns many applications. In addition his or her communication abilities are improved.

Case Studies Winter semester 2001/2002

25. 10. $01 \quad$ Student presentations

1. 11. $01 \quad$ E. Kissling, Geophysics, ETH

Seismic Tomography

8. 11. 01 Xavier Daura, Computational Chemistry, ETH

Computer Simulation in Biochemistry

15. 11. 01 L. Scapozza, Pharmaceutical Biochemistry, ETH

Computational Science within Life Sciences

22. 11. 01 F. Kappel, University of Graz

Modeling of the Cardio Circulatory System

29. 11. $01 \quad$ Student presentations

6. 12. 01 W. Benz, Institute of physics, University of Bern

Formation and Evolution of Planetary Systems

13. 12. 01 Student presentations

20. 12. $01 \quad$ Student presentations

10. 1. 02 A. Troxler, Seminar for Applied Mathematics, ETH Aerodynamic Design of Gas Turbines

17. 1. 02 W. Flury, Esoc / ESA, Darmstadt

Optimization of Inter-planetary Trajectories

Using Solar Electric Propulsion and Gravity

24. 1. 02 Jochen Maurer, Time-steps, Affoltern am Albis

Pricing and Risk Analysis of Energy Portfolios

31. 2. $02 \quad$ Student presentations

7. 2. $02 \quad$ Student presentations 


\section{c) Field of Specialization}

The student has to follow courses in one of the following fields of Specialization: Atmospheric Physics, Computational Chemistry, Computational Fluid Dynamics, Control Theory, Robotics, Theoretical Physics. A field of specialization typically comprises three courses totalling approximately ten hours per week during a semester. Typically one or two of these courses are not computational but provide the student with the scientific or engineering background to be able to understand what one wants to compute in the remaining courses. Typically a student would do one term paper in his or her field of specialization. It is at this point that a student learns to go in depth in one field.

The list of possible fields of specialization depends on the research groups which compute at ETH. To be able to have a field of specialization, such a research group has to guarantee that these three courses are taught regularly every year. This means that the group has to consist of at least two lecturers.

The list is flexible, i.e., as new professors come to ETH new fields can be listed. For example in the near future computational astrophysics and computational biology might be added.

\section{d) Elective Courses}

During their studies a student must attend four elective courses totalling at least 12 hours per week. These courses have to be computational or provide the students with even more scientific or engineering background in her or his field of specialization. A student can use these courses in different ways:

- to deepen the topic treated in a core course.

- to deepen the understanding and knowledge in the chosen field of specialization.

- to get a second field of specialization.

- to broaden the students view by attending additional courses in other areas.

A list of such courses is presented in the Lecture Catalogue. Other choices might be approved by the Studies Advisor, however. The courses often concern research fields where the size of the group is not large enough to sustain a course program for a field of specialization. Moreover, these courses might change every year.

\section{e) Term Papers}

It is here where a student learns to get integrated in a team. He or she is assigned to a running research group which is modelling a problem or which is developing a large code. The time spent is at least 180 hours, which means that during a whole semester of 14 weeks she or he works 3 hours, four afternoons per week. In the first few weeks, members of the group introduce the student to the code and the problem. Then the actual work begins. A term paper is produced in the end and the result is presented to the group and in the 'case studies'. 


\section{f) Supplementary Courses}

As students enter from different backgrounds, they have to do supplementary courses fundamental to CSE. The aim is that upon finishing their studies they all have the same knowledge on the fundamentals and the core courses. How are these supplementary courses determined? A virtual ideal curriculum for the non-existing first two years of studies was determined by the CSE Executive Committee. When a student enters after four semesters of basic education, the courses actually taken are compared to the virtual ideal curriculum. Then it is determined which of the missing lectures he or she still has to follow and which exams have to be taken. For the two-year curricula of 7 departments of the ETH, the supplementary courses to be taken by the student following the CSE program are predetermined. For all others, especially the ones coming from outside of ETH, the Studies Advisor determines the supplementary courses.

\section{g) Diploma Thesis}

The time to complete a diploma thesis is four months. Generally it is done right after the final examination following 2 years of studies in CSE, the topics being from similar fields as the term papers.

\section{Organizational structure}

The general problem with a curriculum such as CSE is the following. Since the focus is on science and engineering, it is preferred to have the professors remaining in the department where their scientific or engineering interest lies. Hence the computational fluid dynamics person will stay in mechanical engineering, the applied mathematician in mathematics, the computational chemistry person in chemistry. It is believed that in this way the continuity of high quality research is better maintained. The curriculum involves in this way many departments and this makes things complicated.

At ETH a curriculum has to be attached to one department and hence the question arose to which one the CSE curriculum should be attached, e.g., to Computer Science or Mathematics. Fortunately, ETH has a long tradition that the Physics and the Mathematics Department do their curricula by a common body, the so called 'Unterrichtskonferenz' (Conference for teaching). All lecturers in mathematics and physics are members of this body. In addition, if a topic in CSE arises, a certain representation of the CSE lecturers are invited too. This representation consists of the Studies Advisor, the CSE Executive Committee, the coordinators for the fields of specialization and the lecturers of the core courses as well as the courses of the fields of specialization. The most active part of the CSE structure is the small CSE Executive Committee, which has only six members (the Studies Advisor, five members from different departments, one of them acting as secretary of the committee). This construction is very good in the sense that it reduces the number of meetings and the number of persons having to sit in meetings. However this structure will have to evolve in time too. 


\section{Experiences and future development}

What are the experiences from the past years? On the positive side we have to mention that the program attracted extremely good students. The grades in their Diploma examination have been on average higher than in traditional curricula. In addition, they were all very fine personalities. On the downside one has to mention that the number is still small. While in 199711 entered the program, 2 of which withdrew, last year 15 entered. What are the reasons for this? The program is difficult for the students, because we use mostly existing courses from other curricula and this means that conflicts in schedule can not be avoided. Hence, often a student learns partly from the professor's manuscript because he or she can not attend all lectures. However, as ETH hires more and more computationally oriented scientists, we will have the staff to make more courses taught for CSE students only. In addition, the number of supplementary courses which have to be taken and the additional examinations which have to be passed turned out to make the studies even harder. This number will be reduced therefore, starting this coming autumn. For the above reasons, the students often feel overloaded. Since there have not been many courses for the CSE students alone, some felt that they were missing an identity. Again, this problem will be eased once more professors in this area are hired. The students did appreciate that they had close contact and much advice from the Secretary of the CSE Executive Committee and from the Studies Advisor. The low number of students is also probably due to the fact that CSE is still not a very common curriculum, it is also very difficult to reach people in the middle of their studies and to motivate them to change.

On the positive side one can mention that last year 10 students did their diploma thesis and thus finished successfully the program, see [1], p. 11. Of these, 4 chose Computational Fluid Dynamics as their specialization, 4 chose robotics, 1 chose theoretical physics and 1 atmospheric physics. In addition, contrary to expectation most students wanted to go on and do a Ph.D.

On the positive side for ETH, the fact is that this additional curriculum does not cost very much. 15'000 CHF each year are used for the course 'case studies' and some other items. The senior scientist who is the secretary of the CSE Executive Committee uses about $60 \%$ of his time for running the curriculum. In addition, colleagues have been positively motivated to review and renew the contents of their courses, and new courses were created. The most interesting one was the course in computational physics. This was needed to make physics a Field of Specialization. Now, there are much more physics students in this course, than students from CSE. We expect this to happen in other new courses too.

What are the changes for the future? As ETH will change from the Diploma system to a Bachelor and Master system, the CSE curriculum will have to undergo change too. We expect this to happen in autumn 2003. With this change, ETH will abolish the 2nd year examination. With the present system it was natural to move from a classical curriculum to the CSE curriculum right after 
this second year examination. Whether one will still be able to change after two years of studies or not, will have to be discussed.

In another move ETH decided last year to create three professorships in CSE. One has been filled last year by a professor who used to be in computational fluid dynamics. Currently this increased manpower is used to strengthen the CSE part in different curricula, such as in mechanical engineering, in computer science and in biology. In addition, an interdepartmental Center for CSE is planned.

\section{Conclusions}

At ETH a CSE program to obtain a Diploma (M.S.) was successfully started in 1997. It builds mainly on existing courses, but is flexible enough so as to accommodate the change in the faculty, which definitely moves to more scientists using computation as a major tool in their research. The focus is on science and engineering and not on computing for the sake of it. A small number of students have entered and successfully finished the program with very high marks. It is planned that most courses will be taught in English as soon as possible. A Bachelor and a Master program are considered. The curriculum in CSE has been very interesting and changes had to be implemented in a flexible and fast way. This will definitely remain so in the coming years.

For more information on the curriculum see the web page www.cse.ethz.ch. Reference [1] can be ordered from the Seminar for Applied Mathematics, ETH Zurich, CH-8092 Zurich.

\section{References}

1. CSE Computational Science and Engineering, Annual Report 2000/2001, R. Jeltsch, K. Nipp, W. van Gunsteren, edits., ETH Zurich, 2001

2. O. Nevanlinna, Interview with Bjoern Engquist, interviewer O. Nevanlinna, EMSNewsletter June 2001, p 15

3. SIAM Working Group on CSE Education, Graduate Education in Computational Science and Engineering, SIAM Rev.43, (2001), 163-177 